\title{
Multiple Human Papilloma Virus (HPV) Infections Are Associated with HSIL and Persistent HPV Infection Status in Korean Patients
}

\author{
Moonsik Kim, Nora Jee-Young Park (D, Ji Yun Jeong $(D)$ and Ji Young Park *
}

check for updates

Citation: Kim, M.; Park, N.J.-Y.; Jeong, J.Y.; Park, J.Y. Multiple Human Papilloma Virus (HPV) Infections Are Associated with HSIL and Persistent HPV Infection Status in Korean Patients. Viruses 2021, 13, 1342. https://doi.org/10.3390/v13071342

Academic Editor: Merilyn Hibma

Received: 9 June 2021

Accepted: 8 July 2021

Published: 12 July 2021

Publisher's Note: MDPI stays neutral with regard to jurisdictional claims in published maps and institutional affiliations.

Copyright: (c) 2021 by the authors. Licensee MDPI, Basel, Switzerland. This article is an open access article distributed under the terms and conditions of the Creative Commons Attribution (CC BY) license (https:/ / creativecommons.org/licenses/by/ $4.0 /)$.
Department of Pathology, Kyungpook National University Chilgok Hospital, Kyungpook National University School of Medicine, Daegu 41566, Korea; teiroa83@knuh.kr (M.K.); pathpjy@naver.com (N.J.-Y.P.); jjiyun@gmail.com (J.Y.J.)

* Correspondence: jyparkmd@knu.ac.kr; Tel.: +82-53-200-3408 or +82-1099415245

\begin{abstract}
Infections with multiple human papilloma virus (HPV) types have been reported, but their role in cervical carcinogenesis has not been fully elucidated. In this study, 236 cases with multiple HPV infection were examined and compared to 180 cases with single HPV infection. HPV genotyping was performed with cervico-vaginal swab specimens using multiplex (real-time) polymerase chain reaction (PCR). In multiple HPV infection, the most prevalent HPV genotype was HPV 53, followed by HPV 16, 58, 52, and 68. HPV 33, 35, 39, 51, 52, 53, 58, and 68 were high-risk-HPV (HR-HPV) genotypes that were more frequently detected in multiple HPV infection compared to that in single HPV infection. The association between multiple HPV infection and high-grade SIL (HSIL) was significantly stronger compared to that of single HPV infection and HSIL $(p=0.002)$. Patients with multiple HPV infection displayed persistent and longer duration of the HPV infection compared to patients with single HPV infection. Multiple HPV infections have distinct clinicopathologic characteristics. Since it is associated with persistent HPV infection, HSIL, and different HR-HPV strains in contrast to single HPV infection, the presence of multiple HPV infection should be reported; close follow up is warranted.
\end{abstract}

Keywords: HPV; multiple infection; HPV genotype; cervical neoplasia

\section{Introduction}

Human papillomavirus (HPV) infection is the major cause of cervical cancers and their precursor lesions [1,2]. Thus far, $>200 \mathrm{HPV}$ genotypes have been identified [3,4]. It is now evident that specific high-risk (HR) types of HPV cause the majority of squamous cell carcinomas (SQCCs) of the cervix as well as their precursors [5], although there are a few HPV-independent cervical SQCCs [6,7]. To date, $>18$ anogenital HPVs have been classified as oncogenic, these include HPV 16, 18, 26, 31, 33, 35, 39, 45, 51, 52, 53, 56, 58, 59, 66, 68, 69, 73, and 82 [8,9]. Although HPV 16, 18, 31, and 51 are common HR-HPV genotypes [9,10], the distribution pattern of HPV genotypes shows diverse regional variation [11-14]. For example, HPV 18, 52, and 58 are reported to be more prevalent in Asian populations [15].

Infection with multiple HPV types is reported in $20-45 \%$ of infected women $[13,16,17]$, depending on the method of diagnosis [18,19]; however, the clinicopathologic significance remains debated, which can be attributed to the methodological diversities, lack of standardization of HPV tests, and indefinite selection from the test identities [20-22]. However, the results of some studies were significant; Brot et al. reported that multiple HR-HPV infection is associated with persistent low-grade squamous intraepithelial lesion (LSIL) and may help to identify patients at a higher risk of progression to high-grade squamous intraepithelial lesion (HSIL) and cervical SQCC [23]. In contrast, Salazar et al. suggested that multiple HPV infections may trigger intergenotypic competition and immune response, and thus do not contribute to the development of SIL [24]. 
HPV vaccines are a breakthrough in the prevention of major cervical cancers and greatly reduce cervical cancer rates. At present, three types of commercial vaccines are available: bivalent (HPV 16, 18), quadrivalent (HPV 16, 18, 6, 11), and nine-valent (HPV $16,18,6,11,31,33,45,52,58)$ vaccines $[25,26]$. It is essential to understand the nature of multiple HPV infection to establish prevention methods, including vaccination. In this study, we evaluated the clinicopathologic characteristics of multiple HPV infection, including infection prevalence, distribution of HPV genotype, and the association between cervical cancer and their precursor lesions compared to single HPV infection.

\section{Materials and Methods}

\subsection{Study Population}

Among 1967 cases wherein HPV genotyping tests were performed, we retrospectively found 236 consecutive cases $(236 / 1967,11.9 \%)$ with confirmed multiple HPV infection between 2017 and 2019 (Figure 1). For the control group, 180 cases of single HPV infection in the same period were randomly selected. Follow-up HPV genotyping tests were performed in each 6-12 month interval. All the patients underwent HPV genotyping tests because of health check-ups, abnormal cytology tests, or biopsy results. Clinicopathologic data of the patients including age, cytology and biopsy results, and duration of HPV infection were retrieved from their medical records.

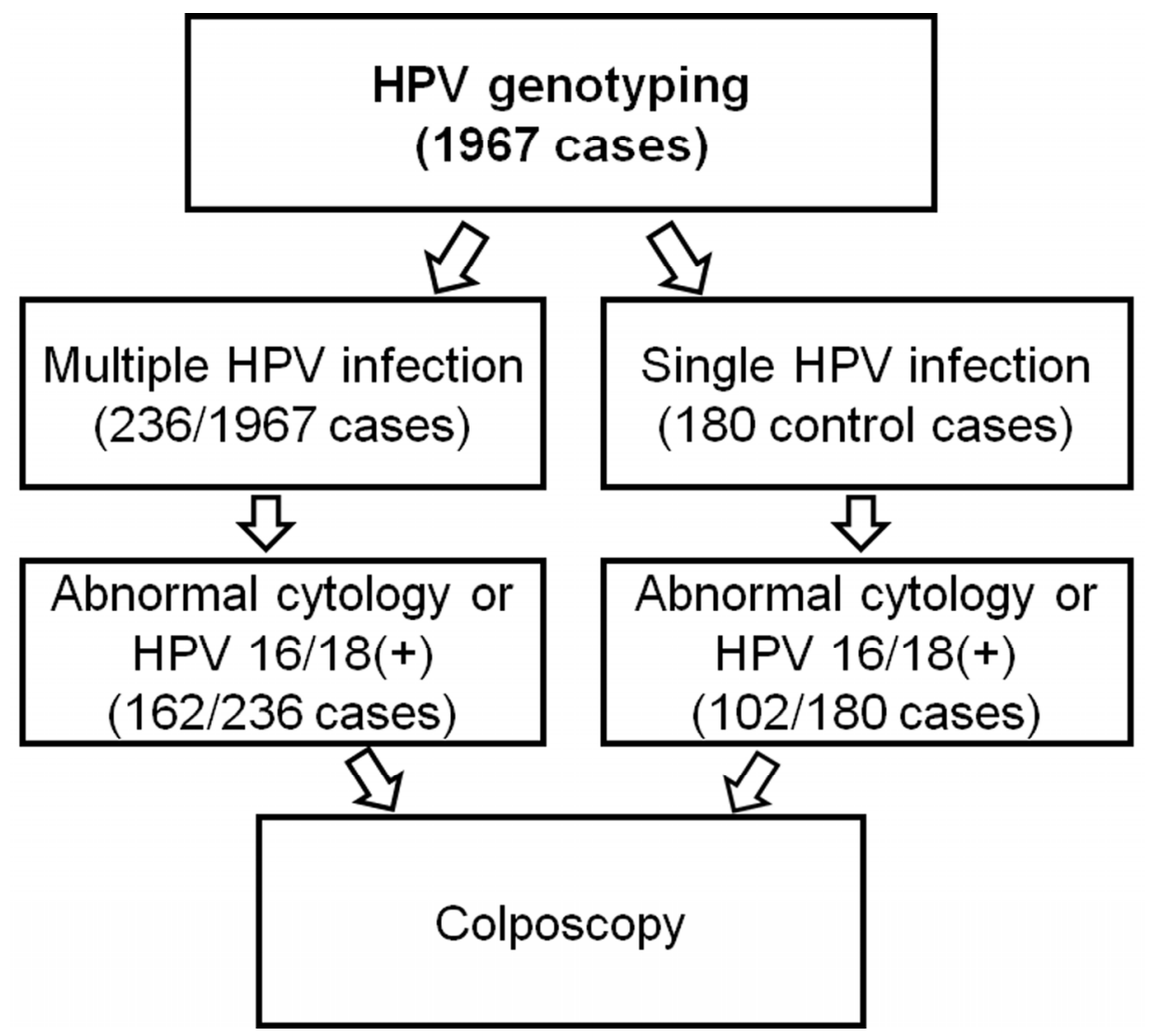

Figure 1. Selection of study cases.

\subsection{Cytological Testing}

Liquid-based Papanicolaou tests (SurePath; BD, Franklin Lakes, NJ, USA) were performed for cytological evaluation. Two experienced gynecologic pathologists (JYJ and NJP) at Kyungpook National University Chilgok Hospital interpreted the cytologic findings, as per the 2001 Bethesda System for cervicovaginal cytology reporting. 


\subsection{HPV Genotyping}

HPV genotyping was performed with cervicovaginal swab specimens using the Anyplex II HPV28 assay kit (Seegene, Seoul, Korea). DNA extraction was carried out following the manufacturer's instructions. Briefly, $5 \mu \mathrm{L}$ of DNA was used in each of two $20 \mu \mathrm{L}$ reactions with primer set A or B. In the assay, HPV-specific dual priming oligonucleotides were used for multiplex (real-time) polymerase chain reaction (PCR). A total of $28 \mathrm{HPV}$ types were tested to simultaneously detect 18 HR types (HPV16, 18, 26, $31,33,35,39,45,51,52,56,58,59,66,68,69,73$, and 82) and 8 low-risk types (HPV 6, 11, $40,42,44,53,54$, and 70). Persistent HPV infection was defined as the detection of any HPV genotype in two consecutive genotyping tests (first test and a follow-up test) [27]. The follow-up interval was 6-12 months for most patients (average follow-up interval: 10.2 months).

\subsection{Pathologic Evaluation}

From a total of 416 cases, comprising 236 multiple HPV infections and 180 single HPV infections detected by HPV genotyping tests, 264 cases with abnormal cervical screening tests (162 multiple and 102 single HPV infection cases) underwent colposcopyguided cervical biopsy (Figure 1). Cervical cytology results corresponding to ASCUS or worse were regarded as abnormal. HPV 16/18 positivity with negative cervical cytology results was also considered abnormal according to the ASCCP consensus guidelines [28]. Cervical biopsies were gathered during the entire follow-up, including the first consultation. Pathologic diagnosis on the corresponding tissue specimens was independently reviewed by two gynecologic pathologists (JYJ and NJP) in a blinded manner. Cases with discrepant results were repeatedly reviewed until a consensus was reached.

\subsection{Statistical Analysis}

Relationships between clinicopathologic parameters were evaluated using the chisquare test for categorical parameters and Fisher's exact test for parameters with an expected frequency of $<5$. We used the Kaplan-Meier method to evaluate the duration of $\mathrm{HPV}$ infection. Statistical differences in the duration of the infection were determined using the log-rank test. Differences were considered significant at $p<0.05$. For multiple comparisons, an adjusted p-value was applied using the Bonferroni correction. All statistical analyses were conducted using IBM SPSS Statistics v.23 (IBM, Armonk, NY, USA).

\section{Results}

\subsection{Overall Prevalence of Multiple and Single HPV Infection}

The average age of the patients was 56.3 years in multiple HPV infection and 53.8 years in single HPV infection. HPV $53(27.5 \%)$ was the most prevalent genotype in multiple HPV infection, followed by HPV $16(21.8 \%), 58(21.2 \%), 52(20.8 \%)$, and $68(20.8 \%)$. HPV $16(15.6 \%)$ was the most prevalent genotype in single HPV infection, followed by HPV $56(11.7 \%), 53(8.3 \%), 52(7.8 \%)$, and 68 (7.2\%). Among HR-HPV, HPV $33(p<0.001)$, $35(p<0.001), 39(p<0.001), 51(p<0.001), 52(p=0.001), 53(p<0.001), 58(p<0.001)$, and $68(p<0.001)$ were more frequently detected in multiple HPV infection than in single HPV infection. Detailed information on HPV infection status is presented in Figure 2, Table 1, and Supplementary Table S1. 
Table 1. Distribution of HPV genotypes (single and multiple infection).

\begin{tabular}{|c|c|c|c|c|}
\hline \multirow[b]{2}{*}{ Total } & \multirow{2}{*}{$\begin{array}{c}\text { Number } \\
416\end{array}$} & \multicolumn{2}{|c|}{ HPV Infection Status } & \multirow[t]{2}{*}{$p$-Value } \\
\hline & & Multiple (236) & Single (180) & \\
\hline Age (mean) & & 56.3 & 53.8 & 0.065 \\
\hline \multicolumn{5}{|l|}{ HR HPV } \\
\hline 16 & & $52(22.0 \%)$ & $28(15.6 \%)$ & 0.125 \\
\hline 18 & & $14(5.9 \%)$ & $8(4.4 \%)$ & 0.652 \\
\hline 26 & & $0(0.0 \%)$ & $1(0.6 \%)$ & 0.892 \\
\hline 31 & & $14(5.9 \%)$ & $4(2.2 \%)$ & 0.11 \\
\hline 33 & & $31(13.1 \%)$ & $2(1.1 \%)$ & $<0.001^{a}$ \\
\hline 35 & & $27(11.4 \%)$ & $1(0.6 \%)$ & $<0.001^{a}$ \\
\hline 39 & & $32(13.6 \%)$ & $1(0.6 \%)$ & $<0.001^{a}$ \\
\hline 45 & & $6(2.5 \%)$ & $2(1.1 \%)$ & 0.488 \\
\hline 51 & & $30(12.7 \%)$ & $4(2.2 \%)$ & $<0.001^{a}$ \\
\hline 52 & & $48(20.3 \%)$ & $14(7.8 \%)$ & $0.001^{\mathrm{a}}$ \\
\hline 53 & & $65(27.5 \%)$ & $15(8.3 \%)$ & $<0.001^{a}$ \\
\hline 56 & & $33(14.0 \%)$ & $21(11.7 \%)$ & 0.583 \\
\hline 58 & & $50(21.2 \%)$ & $8(4.4 \%)$ & $<0.001^{\mathrm{a}}$ \\
\hline 59 & & $11(4.7 \%)$ & $0(0.0 \%)$ & 0.009 \\
\hline 66 & & $32(13.6 \%)$ & $8(4.4 \%)$ & 0.003 \\
\hline 68 & & $49(20.8 \%)$ & $13(7.2 \%)$ & $<0.001^{a}$ \\
\hline 69 & & $4(1.7 \%)$ & $0(0.0 \%)$ & 0.212 \\
\hline 73 & & $2(0.8 \%)$ & $2(1.1 \%)$ & 1 \\
\hline 82 & & $5(2.1 \%)$ & $1(0.6 \%)$ & 0.363 \\
\hline \multicolumn{5}{|l|}{ LR HPV } \\
\hline 6 & & $4(1.7 \%)$ & $3(1.7 \%)$ & 1 \\
\hline 11 & & $1(0.4 \%)$ & $0(0.0 \%)$ & 1 \\
\hline 30 & & $0(0.0 \%)$ & $0(0.0 \%)$ & $\mathrm{N} / \mathrm{A}$ \\
\hline 32 & & $0(0.0 \%)$ & $0(0.0 \%)$ & $\mathrm{N} / \mathrm{A}$ \\
\hline 34 & & $0(0.0 \%)$ & $0(0.0 \%)$ & $\mathrm{N} / \mathrm{A}$ \\
\hline 40 & & $12(5.1 \%)$ & $2(1.1 \%)$ & 0.051 \\
\hline 42 & & $16(6.8 \%)$ & $12(6.7 \%)$ & 1 \\
\hline 43 & & $8(3.4 \%)$ & $5(2.8 \%)$ & 0.943 \\
\hline 44 & & $10(4.2 \%)$ & $1(0.6 \%)$ & 0.044 \\
\hline 54 & & $28(11.9 \%)$ & $8(4.4 \%)$ & 0.013 \\
\hline 55 & & $0(0.0 \%)$ & $0(0.0 \%)$ & $\mathrm{N} / \mathrm{A}$ \\
\hline 61 & & $22(9.3 \%)$ & $11(6.1 \%)$ & 0.309 \\
\hline 62 & & $0(0.0 \%)$ & $0(0.0 \%)$ & $\mathrm{N} / \mathrm{A}$ \\
\hline 67 & & $0(0.0 \%)$ & $0(0.0 \%)$ & $\mathrm{N} / \mathrm{A}$ \\
\hline 70 & & $19(8.1 \%)$ & $10(5.6 \%)$ & 0.426 \\
\hline 74 & & $0(0.0 \%)$ & $0(0.0 \%)$ & $\mathrm{N} / \mathrm{A}$ \\
\hline 81 & & $1(0.4 \%)$ & $0(0.0 \%)$ & 1 \\
\hline 83 & & $0(0.0 \%)$ & $0(0.0 \%)$ & $\mathrm{N} / \mathrm{A}$ \\
\hline 84 & & $0(0.0 \%)$ & $0(0.0 \%)$ & $\mathrm{N} / \mathrm{A}$ \\
\hline 87 & & $0(0.0 \%)$ & $0(0.0 \%)$ & $\mathrm{N} / \mathrm{A}$ \\
\hline 90 & & $0(0.0 \%)$ & $0(0.0 \%)$ & $\mathrm{N} / \mathrm{A}$ \\
\hline
\end{tabular}

a Significant $p$-value after Bonferroni correction (corrected $p$-value: 0.05/40 $=0.0125$; all $40 \mathrm{HPV}$ types were included) was found between single and multiple HPV infection groups. 
A

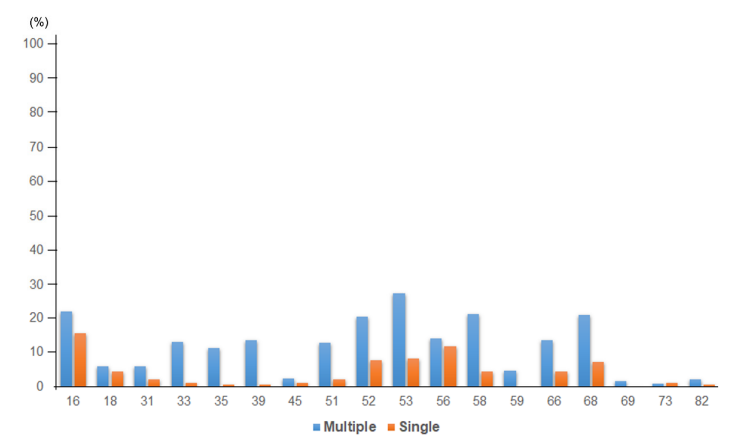

\section{B}

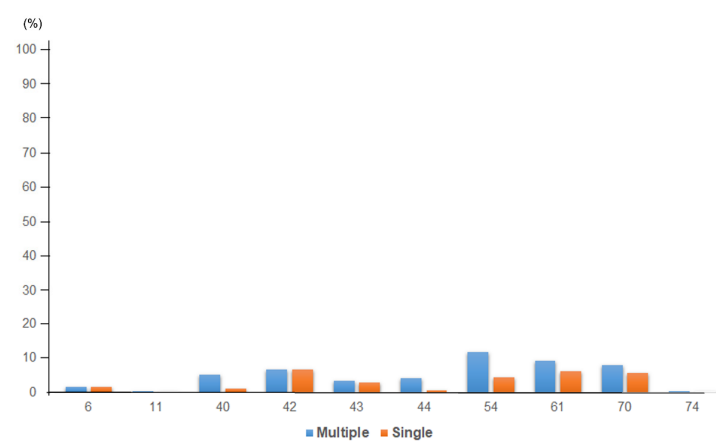

Figure 2. HPV genotype prevalence in single and multiple HPV infection (A) among HR-HPV and (B) LR-HPV.

\subsection{HPV Infection Status in Association with Histology}

Next, we investigated the HPV infection status in association with the cervical lesion grades (Table 2). HSIL was associated significantly more with multiple HPV infection $(76 / 236,33.2 \%)$ compared to that of single HPV infection $(33 / 180,18.3 \% ; p=0.002)$. LSIL was also more frequently found in multiple HPV infection $(37 / 236,15.7 \%)$ compared to that in single HPV infection $(18 / 180,10.0 \%)$, although it was not statistically significant. There was no major difference in the proportion of SQCC or adenocarcinoma (ADC) between the single $(30 / 180,16.7 \%)$ and multiple HPV infection groups $(29 / 236,12.3 \%)$. SIL was found to be more frequently negative in single HPV infection group (94/180,52.2\%) compared to that in the multiple HPV infection group $(91 / 236,38.6 \% ; p=0.007)$. Most of the HSILs, SQCCs, or ADCs were associated with HR-HPV infection (Table 3); only six cases of single HPV infection (HPV 6, 42, 43, 54, 61, and 70) and one case of multiple HPV infection (HPV 6 and 42) progressed to HSIL, SQCC, or ADC without evidence of HR-HPV infection. In the multiple HPV infection group, HPV 16 was also the most prevalent HPV strain among HSIL $(25 / 76,32.9 \%)$ or SQCC $(11 / 29,37.9 \%)$ (Table 3). There was no specific co-infection pattern with HPV 16 and the other HPV strain. Although HPV 16 infection was most frequently associated with HSIL (32.9\%) or SQCC (37.9\%) in multiple HPV infection, other variable HR-HPV strains also contributed to HSIL or SQCC compared to the single HPV infection group. (Figure 3 and Supplementary Table S2). Patients with HSIL frequently had HPV $53(27.6 \%), 58(27.6 \%), 68(25.0 \%), 66(18.4 \%), 33(18.4 \%), 35(15.8 \%)$, and $39(13.2 \%)$, and patients with SQCC had HPV $52(20.7 \%), 18(17.2 \%), 35(17.2 \%)$, and $58(13.8 \%)$ in addition to HPV 16 (Table 3).

A

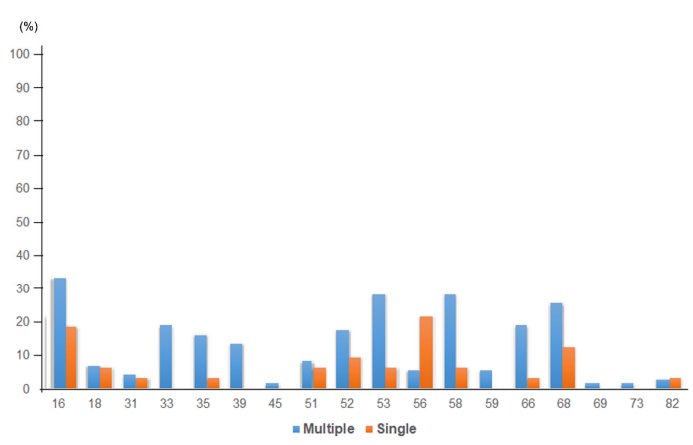

B

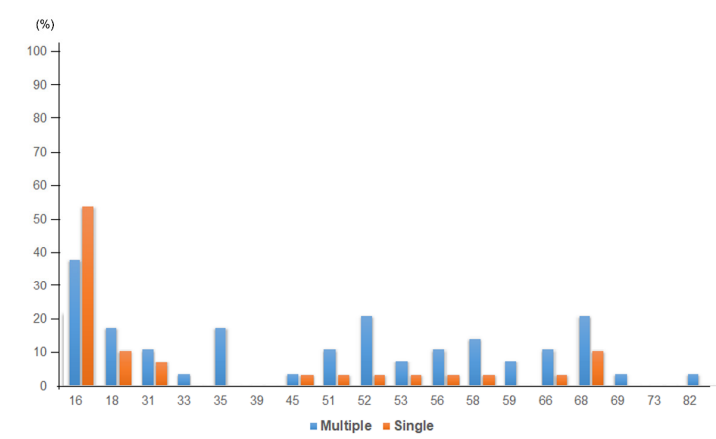

Figure 3. HPV genotype prevalence in (A) HSIL and (B) SQCC (single and multiple infection). 
Table 2. Correlation between histologic diagnosis and HPV infection status (single and multiple).

\begin{tabular}{|c|c|c|c|c|}
\hline \multirow[b]{2}{*}{ Total } & \multirow{2}{*}{$\begin{array}{l}\text { No. } \\
416\end{array}$} & \multicolumn{2}{|c|}{ HPV Infection Status } & \multirow[t]{2}{*}{$p$-Value } \\
\hline & & Multiple (236) & Single (180) & \\
\hline Age (mean) & & 56.3 & 53.8 & \\
\hline \multicolumn{5}{|l|}{ Histology } \\
\hline Normal & 185 & $91(38.6 \%)$ & $94(52.2 \%)$ & 0.007 \\
\hline LSIL & 55 & $37(15.7 \%)$ & $18(10.0 \%)$ & 0.122 \\
\hline HSIL & 110 & $76(32.2 \%)$ & $33(18.3 \%)$ & 0.002 \\
\hline Squamous cell carcinoma & 63 & $29(12.3 \%)$ & $30(16.7 \%)$ & 0.26 \\
\hline Adenocarcinoma & 8 & $3(1.2 \%)$ & $5(2.8 \%)$ & 0.454 \\
\hline
\end{tabular}

Table 3. Association between histologic diagnosis and HPV genotypes (single and multiple HPV infection).

\begin{tabular}{|c|c|c|c|c|c|c|c|c|c|c|}
\hline & \multicolumn{5}{|c|}{ Multiple HPV Infection } & \multicolumn{5}{|c|}{ Single HPV Infection } \\
\hline & Normal & LSIL & HSIL & SQCC & ADC & Normal & LSIL & HSIL & SQCC & ADC \\
\hline & $(n=91)$ & $(n=37)$ & $(n=76)$ & $(n=29)$ & $(n=3)$ & $(n=94)$ & $(n=18)$ & $(n=33)$ & $(n=30)$ & $(n=5)$ \\
\hline \multicolumn{11}{|c|}{ HR HPV } \\
\hline 16 & $13(14.3 \%)$ & $3(8.1 \%)$ & $25(32.9 \%)$ & $11(37.9 \%)$ & $0(0.0 \%)$ & $4(4.3 \%)$ & $0(0.0 \%)$ & $6(18.2 \%)$ & $16(53.3 \%)$ & $2(40.0 \%)$ \\
\hline 18 & $4(4.4 \%)$ & $0(0.0 \%)$ & $5(6.6 \%)$ & $5(17.2 \%)$ & $0(0.0 \%)$ & $2(2.1 \%)$ & $0(0.0 \%)$ & $2(6.1 \%)$ & $3(10.0 \%)$ & $1(20.0 \%)$ \\
\hline 31 & $5(5.5 \%)$ & $3(8.1 \%)$ & $3(3.9 \%)$ & $3(10.3 \%)$ & $0(0.0 \%)$ & $1(1.1 \%)$ & $0(0.0 \%)$ & $1(3.0 \%)$ & $2(6.7 \%)$ & $0(0.0 \%)$ \\
\hline 33 & $10(11.0 \%)$ & $5(13.5 \%)$ & $14(18.4 \%)$ & $1(3.4 \%)$ & $1(33.3 \%)$ & $1(1.1 \%)$ & $1(5.6 \%)$ & $0(0.0 \%)$ & $0(0.0 \%)$ & $0(0.0 \%)$ \\
\hline 35 & $7(7.7 \%)$ & $3(8.1 \%)$ & $12(15.8 \%)$ & $5(17.2 \%)$ & $0(0.0 \%)$ & $0(0.0 \%)$ & $0(0.0 \%)$ & $1(3.0 \%)$ & $0(0.0 \%)$ & $0(0.0 \%)$ \\
\hline 39 & $14(15.4 \%)$ & $6(16.2 \%)$ & $10(13.2 \%)$ & $0(0.0 \%)$ & $2(66.7 \%)$ & $1(1.1 \%)$ & $0(0.0 \%)$ & $0(0.0 \%)$ & $0(0.0 \%)$ & $0(0.0 \%)$ \\
\hline 45 & $2(2.2 \%)$ & $2(5.4 \%)$ & $1(1.3 \%)$ & $1(3.4 \%)$ & $0(0.0 \%)$ & $1(1.1 \%)$ & $0(0.0 \%)$ & $0(0.0 \%)$ & $1(3.3 \%)$ & $0(0.0 \%)$ \\
\hline 51 & $15(16.5 \%)$ & $6(16.2 \%)$ & $6(7.9 \%)$ & $3(10.3 \%)$ & $0(0.0 \%)$ & $1(1.1 \%)$ & $0(0.0 \%)$ & $2(6.1 \%)$ & $1(3.3 \%)$ & $0(0.0 \%)$ \\
\hline 52 & $16(17.6 \%)$ & $12(32.4 \%)$ & $13(17.1 \%)$ & $6(20.7 \%)$ & $1(33.3 \%)$ & $9(9.6 \%)$ & $1(5.6 \%)$ & $3(9.1 \%)$ & $1(3.3 \%)$ & $0(0.0 \%)$ \\
\hline 53 & 27 (29.7\%) & $14(37.8 \%)$ & $21(27.6 \%)$ & $2(6.9 \%)$ & $1(33.3 \%)$ & $12(12.8 \%)$ & $0(0.0 \%)$ & $2(6.1 \%)$ & $1(3.3 \%)$ & $0(0.0 \%)$ \\
\hline 56 & $19(20.9 \%)$ & $7(18.9 \%)$ & $4(5.3 \%)$ & $3(10.3 \%)$ & $0(0.0 \%)$ & $10(10.6 \%)$ & $3(16.7 \%)$ & $7(21.2 \%)$ & $1(3.3 \%)$ & $0(0.0 \%)$ \\
\hline 58 & $21(23.1 \%)$ & $4(10.8 \%)$ & $21(27.6 \%)$ & $4(13.8 \%)$ & $0(0.0 \%)$ & $3(3.2 \%)$ & $2(11.1 \%)$ & $2(6.1 \%)$ & $1(3.3 \%)$ & $0(0.0 \%)$ \\
\hline 59 & $3(3.3 \%)$ & $2(5.4 \%)$ & $4(5.3 \%)$ & $2(6.9 \%)$ & $0(0.0 \%)$ & $0(0.0 \%)$ & $0(0.0 \%)$ & $0(0.0 \%)$ & $0(0.0 \%)$ & $0(0.0 \%)$ \\
\hline 66 & $9(9.9 \%)$ & $6(16.2 \%)$ & $14(18.4 \%)$ & $3(10.3 \%)$ & $0(0.0 \%)$ & $6(6.4 \%)$ & $0(0.0 \%)$ & $1(3.0 \%)$ & $1(3.3 \%)$ & $0(0.0 \%)$ \\
\hline 68 & $19(20.9 \%)$ & $5(13.5 \%)$ & $19(25.0 \%)$ & $6(20.7 \%)$ & $0(0.0 \%)$ & $3(3.2 \%)$ & $2(11.1 \%)$ & $4(12.1 \%)$ & $3(10.0 \%)$ & $1(20.0 \%)$ \\
\hline 69 & $1(1.1 \%)$ & $0(0.0 \%)$ & $1(1.3 \%)$ & $1(3.4 \%)$ & $0(0.0 \%)$ & $0(0.0 \%)$ & $0(0.0 \%)$ & $0(0.0 \%)$ & $0(0.0 \%)$ & $0(0.0 \%)$ \\
\hline 73 & $1(1.1 \%)$ & $0(0.0 \%)$ & $1(1.3 \%)$ & $0(0.0 \%)$ & $0(0.0 \%)$ & $2(2.1 \%)$ & $0(0.0 \%)$ & $0(0.0 \%)$ & $0(0.0 \%)$ & $0(0.0 \%)$ \\
\hline 82 & $1(1.1 \%)$ & $1(2.7 \%)$ & $2(2.6 \%)$ & $1(3.4 \%)$ & $0(0.0 \%)$ & $0(0.0 \%)$ & $0(0.0 \%)$ & $1(3.0 \%)$ & $0(0.0 \%)$ & $0(0.0 \%)$ \\
\hline \multicolumn{11}{|c|}{ LR HPV } \\
\hline 6 & $1(1.1 \%)$ & $1(2.7 \%)$ & $2(2.6 \%)$ & $0(0.0 \%)$ & $0(0.0 \%)$ & $1(1.1 \%)$ & $1(5.6 \%)$ & $0(0.0 \%)$ & $1(3.3 \%)$ & $0(0.0 \%)$ \\
\hline 11 & $0(0.0 \%)$ & $1(2.7 \%)$ & $0(0.0 \%)$ & $0(0.0 \%)$ & $0(0.0 \%)$ & $0(0.0 \%)$ & $0(0.0 \%)$ & $0(0.0 \%)$ & $0(0.0 \%)$ & $0(0.0 \%)$ \\
\hline 30 & $0(0.0 \%)$ & $0(0.0 \%)$ & $0(0.0 \%)$ & $0(0.0 \%)$ & $0(0.0 \%)$ & $0(0.0 \%)$ & $0(0.0 \%)$ & $0(0.0 \%)$ & $0(0.0 \%)$ & $0(0.0 \%)$ \\
\hline 32 & $0(0.0 \%)$ & $0(0.0 \%)$ & $0(0.0 \%)$ & $0(0.0 \%)$ & $0(0.0 \%)$ & $0(0.0 \%)$ & $0(0.0 \%)$ & $0(0.0 \%)$ & $0(0.0 \%)$ & $0(0.0 \%)$ \\
\hline 34 & $0(0.0 \%)$ & $0(0.0 \%)$ & $0(0.0 \%)$ & $0(0.0 \%)$ & $0(0.0 \%)$ & $0(0.0 \%)$ & $0(0.0 \%)$ & $0(0.0 \%)$ & $0(0.0 \%)$ & $0(0.0 \%)$ \\
\hline 40 & $6(6.6 \%)$ & $2(5.4 \%)$ & $1(1.3 \%)$ & $3(10.3 \%)$ & $0(0.0 \%)$ & $1(1.1 \%)$ & $1(5.6 \%)$ & $0(0.0 \%)$ & $0(0.0 \%)$ & $0(0.0 \%)$ \\
\hline 42 & $4(4.4 \%)$ & $2(5.4 \%)$ & $7(9.2 \%)$ & $2(6.9 \%)$ & $1(33.3 \%)$ & $11(11.7 \%)$ & $0(0.0 \%)$ & $1(3.0 \%)$ & $0(0.0 \%)$ & $0(0.0 \%)$ \\
\hline 43 & $1(1.1 \%)$ & $2(5.4 \%)$ & $4(5.3 \%)$ & $1(3.4 \%)$ & $1(33.3 \%)$ & $1(1.1 \%)$ & $3(16.7 \%)$ & $0(0.0 \%)$ & $1(3.3 \%)$ & $0(0.0 \%)$ \\
\hline 44 & $5(5.5 \%)$ & $0(0.0 \%)$ & $3(3.9 \%)$ & $2(6.9 \%)$ & $0(0.0 \%)$ & $1(1.1 \%)$ & $0(0.0 \%)$ & $0(0.0 \%)$ & $0(0.0 \%)$ & $0(0.0 \%)$ \\
\hline 54 & $11(12.1 \%)$ & $2(5.4 \%)$ & $10(13.2 \%)$ & $4(13.8 \%)$ & $0(0.0 \%)$ & $5(5.3 \%)$ & $1(5.6 \%)$ & $0(0.0 \%)$ & $1(3.3 \%)$ & $1(20.0 \%)$ \\
\hline 55 & $0(0.0 \%)$ & $0(0.0 \%)$ & $0(0.0 \%)$ & $0(0.0 \%)$ & $0(0.0 \%)$ & $0(0.0 \%)$ & $0(0.0 \%)$ & $0(0.0 \%)$ & $0(0.0 \%)$ & $0(0.0 \%)$ \\
\hline 61 & $9(9.9 \%)$ & $2(5.4 \%)$ & $8(10.5 \%)$ & $2(6.9 \%)$ & $0(0.0 \%)$ & $9(9.6 \%)$ & $2(11.1 \%)$ & $0(0.0 \%)$ & $0(0.0 \%)$ & $0(0.0 \%)$ \\
\hline 62 & $0(0.0 \%)$ & $0(0.0 \%)$ & $0(0.0 \%)$ & $0(0.0 \%)$ & $0(0.0 \%)$ & $0(0.0 \%)$ & $0(0.0 \%)$ & $0(0.0 \%)$ & $0(0.0 \%)$ & $0(0.0 \%)$ \\
\hline 67 & $0(0.0 \%)$ & $0(0.0 \%)$ & $0(0.0 \%)$ & $0(0.0 \%)$ & $0(0.0 \%)$ & $0(0.0 \%)$ & $0(0.0 \%)$ & $0(0.0 \%)$ & $0(0.0 \%)$ & $0(0.0 \%)$ \\
\hline 70 & $8(8.8 \%)$ & $4(10.8 \%)$ & $4(5.3 \%)$ & $3(10.3 \%)$ & $0(0.0 \%)$ & $8(8.5 \%)$ & $1(5.6 \%)$ & $1(3.0 \%)$ & $0(0.0 \%)$ & $0(0.0 \%)$ \\
\hline 74 & $0(0.0 \%)$ & $0(0.0 \%)$ & $0(0.0 \%)$ & $0(0.0 \%)$ & $0(0.0 \%)$ & $0(0.0 \%)$ & $0(0.0 \%)$ & $0(0.0 \%)$ & $0(0.0 \%)$ & $0(0.0 \%)$ \\
\hline 81 & $0(0.0 \%)$ & $0(0.0 \%)$ & $0(0.0 \%)$ & $1(3.4 \%)$ & $0(0.0 \%)$ & $0(0.0 \%)$ & $0(0.0 \%)$ & $0(0.0 \%)$ & $0(0.0 \%)$ & $0(0.0 \%)$ \\
\hline 83 & $0(0.0 \%)$ & $0(0.0 \%)$ & $0(0.0 \%)$ & $0(0.0 \%)$ & $0(0.0 \%)$ & $0(0.0 \%)$ & $0(0.0 \%)$ & $0(0.0 \%)$ & $0(0.0 \%)$ & $0(0.0 \%)$ \\
\hline 84 & $0(0.0 \%)$ & $0(0.0 \%)$ & $0(0.0 \%)$ & $0(0.0 \%)$ & $0(0.0 \%)$ & $0(0.0 \%)$ & $0(0.0 \%)$ & $0(0.0 \%)$ & $0(0.0 \%)$ & $0(0.0 \%)$ \\
\hline 87 & $0(0.0 \%)$ & $0(0.0 \%)$ & $0(0.0 \%)$ & $0(0.0 \%)$ & $0(0.0 \%)$ & $0(0.0 \%)$ & $0(0.0 \%)$ & $0(0.0 \%)$ & $0(0.0 \%)$ & $0(0.0 \%)$ \\
\hline 90 & $0(0.0 \%)$ & $0(0.0 \%)$ & $0(0.0 \%)$ & $0(0.0 \%)$ & $0(0.0 \%)$ & $0(0.0 \%)$ & $0(0.0 \%)$ & $0(0.0 \%)$ & $0(0.0 \%)$ & $0(0.0 \%)$ \\
\hline
\end{tabular}

\subsection{Multiple HPV Types Were Associated with Persistent and Longer Duration of HPV Infection}

We evaluated if infection with multiple HPV strains affects the persistence of HPV infection. Multiple HPV types were more significantly associated with persistent HPV infection than single HPV infection $(180 / 193,93.5 \%$ vs. 91/145, 62.8\%, $p<0.001)$. Furthermore, we investigated if there was any correlation between multiple HPV infection 
and the duration of HPV infection. The median follow-up period was 26 months. The infection lasted significantly longer in patients with multiple HPV strains compared to patients infected by a single HPV strain (median period: 68 vs. 27 months, $p<0.001$, Figure $4 \mathrm{~A})$. Longer durations of HPV infection in the multiple HPV genotype group were also identified in subgroups who had HSIL or SQCC (Figure 4B). Among the multiple HPV infection group, there was no association with the duration of HPV infection according to HPV genotypes (Supplementary Figure S1) or combination patterns of HR-HPV or LR-HPV (Supplementary Figure S2).

A

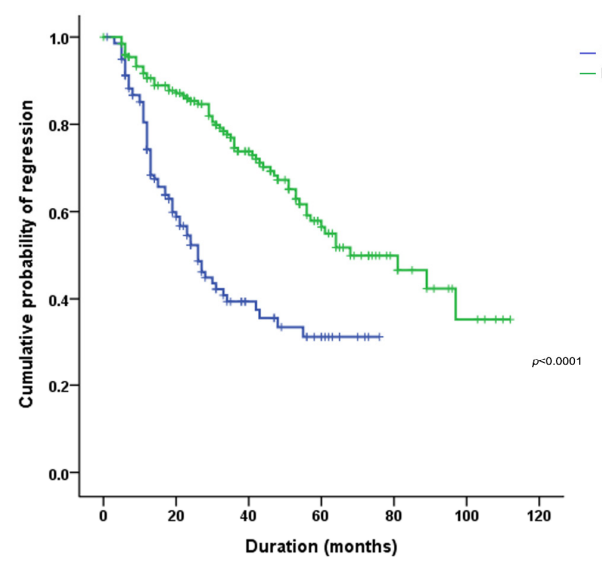

B

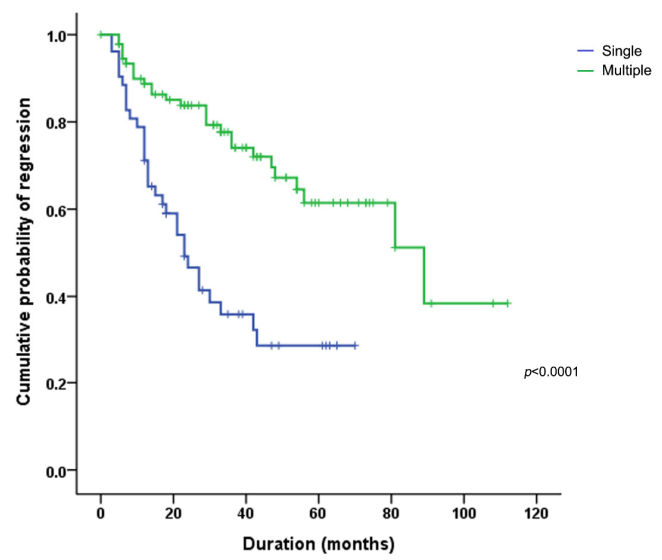

Figure 4. Kaplan-Meier curve of HPV infection during the follow-up period (in single and multiple HPV infections) (A) in all cases and (B) among those who had HSIL and SQCC. Regression was defined as the absence of HPV detection during any follow-up period.

\section{Discussion}

In this study, we demonstrated that: (1) a diverse distribution of HPV genotypes occurs in multiple HPV infections in contrast to single HPV infections, (2) multiple HPV infections are more associated with HSIL and the duration of their infections is longer than that of single HPV infections, and (3) various HR-HPV strains contribute to HSIL or SQCC in addition to HPV 16.

The role of HPV infection in cervical carcinogenesis has been well-established [29]. Although the majority of HPV infections are transient, some HPV infections, especially HR-HPV and longer duration infection types, can progress to HSIL or SQCC [30]. Various risk factors can affect the progression to cervical carcinogenesis, including HPV genotypes, patient age, multiparity, socioeconomic status, and personal life style [31]. However, the role of multiple HPV infection in cervical carcinogenesis is still controversial and requires elucidation.

The prevalence and distribution of multiple and single HPV infections vary widely worldwide and are affected by diverse factors, including age, socioeconomic status, immune status, and vaccination status $[15,32,33]$. In this study, in decreasing order, HPV $53(27.5 \%), 16(21.8 \%), 58(21.2 \%), 52(20.8 \%)$, and $68(20.8 \%)$ were the prevalent genotypes in multiple HPV infection among HR-HPV patients. HPV 53, 58, 52, 68, and other HR-HPV genotypes, which were frequently detected in the current study, were also commonly reported in previous Korean population-based HPV studies [14,34,35]. In addition, HPV $33(p<0.001), 35(p<0.001), 39(p<0.001), 51(p<0.001), 52(p=0.001), 53(p<0.001)$, $58(p<0.001), 59(p=0.009), 66(p=0.003)$, and $68(p<0.001)$ were associated more frequently with multiple than single HPV infection. As most of these genotypes were identified in a similar range of $10-20 \%$ without specific patterns of co-infection or phylogenetically related groups, it is difficult to determine whether this is the result of the synergistic or 
competitive effects of different HPV genotypes or the mere sum of incidental cumulative HPV co-infection.

In our study, HSIL $(76 / 236,33.2 \%)$ was significantly more frequent in multiple HPV infection than in single HPV infection $(33 / 180,18.3 \%, p=0.002)$. LSIL was also more frequently detected in multiple HPV infection $(37 / 236,15.7 \%)$, although statistically not significant. A study by Schimitt et al. also reported that multiple HPV types were prevalent in LSIL and HSIL [36]. It is generally accepted that progression to HSIL and SQCC correlates with monoclonal expansion of HPV-infected host cells [29]; however, some previous studies have suggested that multiple HPV infections confer synergistic impact on the developing SIL $[11,12,37]$, which supports the impact of multiple HPV infections on SIL in this study. Possibly, different HPV genotypes infect different cells in distinct lesions in the same patient; subsequent studies are warranted to validate this hypothesis.

Although this study shows that HPV16 is the major cause of HSIL and SQCC, patients with multiple HPV infection also exhibited comparable amounts of other HR-HPV genotypes, including HPV 33, 35, 39, 53, 58, 66, and 68. Previous studies have demonstrated that the diverse distribution of prevalent genotypes and co-infection patterns of HR-HPVs in HSIL and SQCC depends on demographic and socioeconomic factors [38-40]. Bolaños et al. reported that HPV 51 and 52 co-infections were common in the Mexican population in addition to HPV 16 [38]. Trottier et al. indicated that in addition to HPV 16, co-infections involving HPV 58 appeared to increase cervical oncogenic risk in Brazilian populations [22]. It is possible that synergistic interactions among HR-HPVs other than HPV 16 genotype may have influenced cervical carcinogenesis in our cohort group. Differences regarding immunity status, vaccination status, demographics, and other possible risk factors in Korean patients, who constitute most of the patients in our study, may have affected the distribution of HPV genotypes in multiple HPV infection. Although few HSIL and SQCC had only LR-HPVs without evidence of HR-HPV infections in this study, this is probably due to the insufficiency of previous medical records.

Another noteworthy finding of this study is that patients with multiple HPV genotypes had persistent HPV infection during follow-up periods compared to patients with single HPV infection. Some previous studies have pointed to the possible association between multiple HPV genotypes and persistence of infection [11,20,23,41]. A possible mechanism is that synergistic interactions between multiple HPVs help persistent HPV infection [25,38]. Changes in immune status caused by multiple HPV infections may affect the duration of HPV infection as well [42]. The increased viral load caused by HPV multiplicity is another possible reason for the persistence HPV infection [11].

This study has some limitations. First, the frequency of multiple HPV infections and the distribution pattern of HPV genotypes being influenced by the detection method. AnyplexTM II HPV28 assay is a real-time PCR-based HPV detection method, which is more sensitive compared to the HPV DNA chip assay or the HPV hybrid capture DNA test [43]. Therefore, the prevalence of multiple HPV infections and commonly infected HR-HPV types can be estimated differently on the other detection platforms. In addition, this study was conducted in a single institution with a limited number of cases; there may be different HPV distribution patterns among different regions or countries. Thus, a larger cohort study is warranted to validate the result of this study. Because of the retrospective nature of this study, we were not able to clarify the exact mechanism of multiple HPV infections on the progression of SIL and persistent HPV infection. Thus, further in vitro and in vivo studies are warranted to strengthen the effects of multiple HPV infections suggested in this study.

In conclusion, we demonstrated distinct clinicopathologic characteristics of multiple $\mathrm{HPV}$ infection in comparison to single HPV infection regarding the progression of the infection to SIL and the duration of the infection. Multiple HPV infections were also enriched with diverse HPV genotypes in contrast to single HPV infections. As understanding the distribution pattern and infection mechanism of multiple HPV genotypes is critical for establishing the prevention plans and vaccination programs of HPV, subsequent studies are warranted to further validate the results of this study. 
Supplementary Materials: The following are available online at https:/ / www.mdpi.com/article/10 .3390/v13071342/s1, Table S1: Detailed clinicopathologic characteristics of patient cohort, Table S2: Association between SIL lesion (HSIL and SQCC) and HPV genotypes (single and multiple HPV infection), Figure S1: Regression or persistence of HPV infection during follow-up period according to HPV genotypes (in multiple HPV infection): (A) HPV 16, (B) HPV 18, (C) HPV 53, (D) HPV 58, and (E) HPV 68, Figure S2: Regression or persistence of HPV infection during follow-up period according to HPV genotypes (in multiple HPV infection): (A) Combination patterns of HR- or LR-HPV and (B) number of HPV genotypes.

Author Contributions: J.Y.P. provided the conception and design of the manuscript; M.K. and N.J.-Y.P. drafted the manuscript; J.Y.J. analyzed the previous articles regarding multiple HPV infections; J.Y.J. and J.Y.P. carefully reviewed and revised the manuscript. All authors have read and agreed to the published version of the manuscript.

Funding: This work was supported by Biomedical Research Institute grant, Kyungpook National University Hospital (2017).

Institutional Review Board Statement: The study was conducted according to the guidelines of the Declaration of Helsinki, and approved by the Institutional review board of Kyungpook National University Chilgok Hospital (KNUCH 2019-04-002-002).

Informed Consent Statement: Written informed consent from the patients was waived due to the retrospective nature of the study.

Data Availability Statement: All data generated and analyzed during this study are included in this article and its supplementary information files.

Acknowledgments: The authors are grateful for the support provided by, and wish to thank the Kyungpook National University Chilgok Hospital molecular pathology laboratory.

Conflicts of Interest: The authors declare no conflict of interest.

\section{References}

1. Solomon, D.; Davey, D.; Kurman, R.; Moriarty, A.; O'Connor, D.; Prey, M.; Raab, S.; Sherman, M.; Wilbur, D.; Wright Jr, T. The 2001 Bethesda System: Terminology for reporting results of cervical cytology. JAMA 2002, 287, 2114-2119. [CrossRef]

2. Bosch, F.X.; Lorincz, A.; Muñoz, N.; Meijer, C.; Shah, K.V. The causal relation between human papillomavirus and cervical cancer. J. Clin. Pathol. 2002, 55, 244-265. [CrossRef]

3. Van Doorslaer, K.; Li, Z.; Xirasagar, S.; Maes, P.; Kaminsky, D.; Liou, D.; Sun, Q.; Kaur, R.; Huyen, Y.; McBride, A.A. The Papillomavirus Episteme: A major update to the papillomavirus sequence database. Nucleic Acids Res. 2017, 45, D499-D506. [CrossRef] [PubMed]

4. Bernard, H.U.; Burk, R.D.; Chen, Z.; van Doorslaer, K.; zur Hausen, H.; de Villiers, E.M. Classification of papillomaviruses (PVs) based on 189 PV types and proposal of taxonomic amendments. Virology 2010, 401, 70-79. [CrossRef] [PubMed]

5. Walboomers, J.M.; Jacobs, M.V.; Manos, M.M.; Bosch, F.X.; Kummer, J.A.; Shah, K.V.; Snijders, P.J.; Peto, J.; Meijer, C.J.; Muñoz, N. Human papillomavirus is a necessary cause of invasive cervical cancer worldwide. J. Pathol. 1999, 189, 12-19. [CrossRef]

6. Rodríguez-Carunchio, L.; Soveral, I.; Steenbergen, R.D.; Torné, A.; Martinez, S.; Fusté, P.; Pahisa, J.; Marimon, L.; Ordi, J.; del Pino, M. HPV-negative carcinoma of the uterine cervix: A distinct type of cervical cancer with poor prognosis. BJOG 2015, 122, 119-127. [CrossRef] [PubMed]

7. He, C.; Lv, X.; Huang, C.; Angeletti, P.C.; Hua, G.; Dong, J.; Zhou, J.; Wang, Z.; Ma, B.; Chen, X.; et al. A Human PapillomavirusIndependent Cervical Cancer Animal Model Reveals Unconventional Mechanisms of Cervical Carcinogenesis. Cell Rep. 2019, 26, 2636-2650. [CrossRef]

8. Sakamoto, J.; Kamiura, S.; Okayama, K.; Okodo, M.; Shibata, T.; Osaka, Y.; Fujita, S.; Takata, E.; Takagi, H.; Takakura, M.; et al. Single type infection of human papillomavirus as a cause for high-grade cervical intraepithelial neoplasia and invasive cancer in Japan. Papillomavirus Res. 2018, 6, 46-51. [CrossRef]

9. Muñoz, N.; Bosch, F.X.; De Sanjosé, S.; Herrero, R.; Castellsagué, X.; Shah, K.V.; Snijders, P.J.; Meijer, C.J. Epidemiologic classification of human papillomavirus types associated with cervical cancer. N. Engl. J. Med. 2003, 348, 518-527. [CrossRef]

10. Clifford, G.M.; Smith, J.S.; Aguado, T.; Franceschi, S. Comparison of HPV type distribution in high-grade cervical lesions and cervical cancer: A meta-analysis. Br. J. Cancer 2003, 89, 101-105. [CrossRef]

11. Oyervides-Munoz, M.A.; Perez-Maya, A.A.; Sanchez-Dominguez, C.N.; Berlanga-Garza, A.; Antonio-Macedo, M.; Valdez-Chapa, L.D.; Cerda-Flores, R.M.; Trevino, V.; Barrera-Saldana, H.A.; Garza-Rodriguez, M.L. Multiple HPV Infections and Viral Load Association in Persistent Cervical Lesions in Mexican Women. Viruses 2020, 12, 380. [CrossRef]

12. Bruno, M.T.; Scalia, G.; Cassaro, N.; Boemi, S. Multiple HPV 16 infection with two strains: A possible marker of neoplastic progression. BMC Cancer 2020, 20, 444. [CrossRef] [PubMed] 
13. Li, M.; Du, X.; Lu, M.; Zhang, W.; Sun, Z.; Li, L.; Ye, M.; Fan, W.; Jiang, S.; Liu, A.; et al. Prevalence characteristics of single and multiple HPV infections in women with cervical cancer and precancerous lesions in Beijing, China. J. Med. Virol. 2019, 91, 473-481. [CrossRef] [PubMed]

14. Lee, E.H.; Um, T.H.; Chi, H.S.; Hong, Y.J.; Cha, Y.J. Prevalence and distribution of human papillomavirus infection in Korean women as determined by restriction fragment mass polymorphism assay. J. Korean Med. Sci. 2012, 27, 1091-1097. [CrossRef] [PubMed]

15. Crow, J.M. HPV: The global burden. Nature 2012, 488, S2-S3. [CrossRef] [PubMed]

16. Pista, A.; Oliveira, A.; Verdasca, N.; Ribeiro, F. Single and multiple human papillomavirus infections in cervical abnormalities in Portuguese women. Clin. Microbiol. Infect. 2011, 17, 941-946. [CrossRef] [PubMed]

17. Chaturvedi, A.K.; Katki, H.A.; Hildesheim, A.; Rodriguez, A.C.; Quint, W.; Schiffman, M.; Van Doorn, L.J.; Porras, C.; Wacholder, S.; Gonzalez, P.; et al. Human papillomavirus infection with multiple types: Pattern of coinfection and risk of cervical disease. J. Infect. Dis. 2011, 203, 910-920. [CrossRef] [PubMed]

18. Dickson, E.L.; Vogel, R.I.; Bliss, R.L.; Downs, L.S., Jr. Multiple-type human papillomavirus (HPV) infections: A cross-sectional analysis of the prevalence of specific types in 309,000 women referred for HPV testing at the time of cervical cytology. Int. J. Gynecol. Cancer 2013, 23, 1295-1302. [CrossRef]

19. Vaccarella, S.; Franceschi, S.; Snijders, P.J.; Herrero, R.; Meijer, C.J.; Plummer, M. Concurrent infection with multiple human papillomavirus types: Pooled analysis of the IARC HPV Prevalence Surveys. Cancer Epidemiol. Biomark. Prev. 2010, 19, 503-510. [CrossRef]

20. Campos, N.G.; Rodriguez, A.C.; Castle, P.E.; Herrero, R.; Hildesheim, A.; Katki, H.; Kim, J.J.; Wacholder, S.; Morales, J.; Burk, R.D. Persistence of concurrent infections with multiple human papillomavirus types: A population-based cohort study. J. Infect. Dis. 2011, 203, 823-827. [CrossRef]

21. Gargiulo, F.; De Francesco, M.A.; Schreiber, C.; Ciravolo, G.; Salinaro, F.; Valloncini, B.; Manca, N. Prevalence and distribution of single and multiple HPV infections in cytologically abnormal cervical samples from Italian women. Virus Res. 2007, 125, 176-182. [CrossRef] [PubMed]

22. Trottier, H.; Mahmud, S.; Costa, M.C.; Sobrinho, J.P.; Duarte-Franco, E.; Rohan, T.E.; Ferenczy, A.; Villa, L.L.; Franco, E.L. Human papillomavirus infections with multiple types and risk of cervical neoplasia. Cancer Epidemiol. Biomark. Prev. 2006, 15, 1274-1280. [CrossRef] [PubMed]

23. De Brot, L.; Pellegrini, B.; Moretti, S.T.; Carraro, D.M.; Soares, F.A.; Rocha, R.M.; Baiocchi, G.; da Cunha, I.W.; de Andrade, V.P. Infections with multiple high-risk HPV types are associated with high-grade and persistent low-grade intraepithelial lesions of the cervix. Cancer Cytopathol. 2017, 125, 138-143. [CrossRef]

24. Salazar, K.L.; Zhou, H.S.; Xu, J.; Peterson, L.E.; Schwartz, M.R.; Mody, D.R.; Ge, Y. Multiple Human Papilloma Virus Infections and Their Impact on the Development of High-Risk Cervical Lesions. Acta Cytol. 2015, 59, 391-398. [CrossRef]

25. Senapati, R.; Nayak, B.; Kar, S.K.; Dwibedi, B. HPV genotypes co-infections associated with cervical carcinoma: Special focus on phylogenetically related and non-vaccine targeted genotypes. PLoS ONE 2017, 12, e0187844. [CrossRef] [PubMed]

26. Paavonen, J.; Naud, P.; Salmerón, J.; Wheeler, C.M.; Chow, S.N.; Apter, D.; Kitchener, H.; Castellsague, X.; Teixeira, J.C.; Skinner, S.R.; et al. Efficacy of human papillomavirus (HPV)-16/18 AS04-adjuvanted vaccine against cervical infection and precancer caused by oncogenic HPV types (PATRICIA): Final analysis of a double-blind, randomised study in young women. Lancet 2009, 374, 301-314. [CrossRef]

27. Schiffman, M.; Kjaer, S.K. Chapter 2: Natural history of anogenital human papillomavirus infection and neoplasia. J. Natl. Cancer Inst. Monogr. 2003, 2003, 14-19. [CrossRef]

28. Massad, L.S.; Einstein, M.H.; Huh, W.K.; Katki, H.A.; Kinney, W.K.; Schiffman, M.; Solomon, D.; Wentzensen, N.; Lawson, H.W. 2012 updated consensus guidelines for the management of abnormal cervical cancer screening tests and cancer precursors. J. Low. Genit. Tract Dis. 2013, 17, S1-S27. [CrossRef]

29. Woodman, C.B.; Collins, S.I.; Young, L.S. The natural history of cervical HPV infection: Unresolved issues. Nat. Rev. Cancer 2007, 7, 11-22. [CrossRef] [PubMed]

30. Burchell, A.N.; Winer, R.L.; de Sanjosé, S.; Franco, E.L. Chapter 6: Epidemiology and transmission dynamics of genital HPV infection. Vaccine 2006, 24, S52-S61. [CrossRef] [PubMed]

31. Giuliano, A.R.; Papenfuss, M.; Schneider, A.; Nour, M.; Hatch, K. Risk Factors for High-Risk Type Human Papillomavirus Infection among Mexican-American Women. Cancer Epidemiol. Prev. Biomark. 1999, 8, 615-620.

32. Soto-De Leon, S.; Camargo, M.; Sanchez, R.; Munoz, M.; Perez-Prados, A.; Purroy, A.; Patarroyo, M.E.; Patarroyo, M.A. Distribution patterns of infection with multiple types of human papillomaviruses and their association with risk factors. PLoS ONE 2011, 6, e14705. [CrossRef] [PubMed]

33. Smith, J.S.; Lindsay, L.; Hoots, B.; Keys, J.; Franceschi, S.; Winer, R.; Clifford, G.M. Human papillomavirus type distribution in invasive cervical cancer and high-grade cervical lesions: A meta-analysis update. Int. J. Cancer 2007, 121, 621-632. [CrossRef]

34. Kang, C.-S.; Lee Kyung, E. Prevalence and Genotype Analysis of High Risk-human Papillomavirus Infection in Busan Women. J. Life Sci. 2019, 29, 1267-1272. [CrossRef]

35. So, K.A.; Hong, J.H.; Lee, J.K. Human Papillomavirus Prevalence and Type Distribution Among 968 Women in South Korea. J. Cancer Prev. 2016, 21, 104-109. [CrossRef] [PubMed] 
36. Schmitt, M.; Depuydt, C.; Benoy, I.; Bogers, J.; Antoine, J.; Arbyn, M.; Pawlita, M. Multiple human papillomavirus infections with high viral loads are associated with cervical lesions but do not differentiate grades of cervical abnormalities. J. Clin. Microbiol. 2013, 51, 1458-1464. [CrossRef] [PubMed]

37. Bachtiary, B.; Obermair, A.; Dreier, B.; Birner, P.; Breitenecker, G.; Knocke, T.H.; Selzer, E.; Potter, R. Impact of multiple HPV infection on response to treatment and survival in patients receiving radical radiotherapy for cervical cancer. Int. J. Cancer 2002, 102, 237-243. [CrossRef] [PubMed]

38. Gallegos-Bolanos, J.; Rivera-Dominguez, J.A.; Presno-Bernal, J.M.; Cervantes-Villagrana, R.D. High prevalence of co-infection between human papillomavirus (HPV) 51 and 52 in Mexican population. BMC Cancer 2017, 17, 531. [CrossRef]

39. de Sanjose, S.; Quint, W.G.V.; Alemany, L.; Geraets, D.T.; Klaustermeier, J.E.; Lloveras, B.; Tous, S.; Felix, A.; Bravo, L.E.; Shin, H.-R.; et al. Human papillomavirus genotype attribution in invasive cervical cancer: A retrospective cross-sectional worldwide study. Lancet Oncol. 2010, 11, 1048-1056. [CrossRef]

40. Fife, K.H.; Cramer, H.M.; Schroeder, J.M.; Brown, D.R. Detection of multiple human papillomavirus types in the lower genital tract correlates with cervical dysplasia. J. Med. Virol. 2001, 64, 550-559. [CrossRef]

41. Rousseau, M.-C.; Pereira, J.S.; Prado, J.C.; Villa, L.L.; Rohan, T.E.; Franco, E.L. Cervical coinfection with human papillomavirus (HPV) types as a predictor of acquisition and persistence of HPV infection. J. Infect. Dis. 2001, 184, 1508-1517. [CrossRef] [PubMed]

42. Stanley, M. Immune responses to human papillomavirus. Vaccine 2006, 24, S16-S22. [CrossRef] [PubMed]

43. Baasland, I.; Romundstad, P.R.; Eide, M.L.; Jonassen, C.M. Clinical performance of Anyplex II HPV28 by human papillomavirus type and viral load in a referral population. PLoS ONE 2019, 14, e0210997. [CrossRef] [PubMed] 